\title{
KIF2C Is a Novel Prognostic Biomarker and Correlated with Immune Infiltration in Endometrial Cancer
}

\author{
Lanfen An $\mathbb{D}^{1},{ }^{1}$ Jun Zhang $\mathbb{D}^{1},{ }^{1}$ Dilu Feng ${ }^{\mathbb{D}},{ }^{1}$ Yingchao Zhao ${ }^{\mathbb{D}},{ }^{2}$ Weixiang Ouyang $\mathbb{D}^{1},{ }^{1}$ \\ Rui Shi $\mathbb{D}^{1},{ }^{1}$ Xing Zhou $\mathbb{D}^{1},{ }^{1}$ Zhicheng Yu $\mathbb{D}^{1},{ }^{1}$ Sitian Wei $\mathbb{D}^{1},{ }^{1}$ Jie Min $\mathbb{D}^{1},{ }^{1}$ and Hongbo Wang $\mathbb{D}^{1}$ \\ ${ }^{1}$ Department of Obstetrics and Gynecology, Union Hospital, Tongji Medical College, Huazhong University of Science \\ and Technology, Wuhan 430022, China \\ ${ }^{2}$ Cancer Center, Union Hospital, Tongji Medical College, Huazhong University of Science and Technology, Wuhan 430022, China
}

Correspondence should be addressed to Jie Min; 691055202@qq.com and Hongbo Wang; hb_wang1969@sina.com

Received 20 June 2021; Revised 24 August 2021; Accepted 2 September 2021; Published 5 October 2021

Academic Editor: Qixiang Shao

Copyright (c) 2021 Lanfen An et al. This is an open access article distributed under the Creative Commons Attribution License, which permits unrestricted use, distribution, and reproduction in any medium, provided the original work is properly cited.

\begin{abstract}
Endometrial cancer (EC) is commonly diagnosed cancer in women, and the prognosis of advanced types of EC is extremely poor. Kinesin family member 2C (KIF2C) has been reported as an oncogene in cancers. However, its pathophysiological roles and the correlation with tumor-infiltrating lymphocytes in EC remain unclear. The mRNA and protein levels of KIF2C in EC tissues were detected by qRT-PCR, Western blot (WB), and IHC. CCK8, Transwell, and colony formation assay were applied to assess the effects of KIF2C on cell proliferation, migration, and invasion. Cell apoptosis and cell cycle were analyzed by flow cytometry. The antitumor effect was further validated in the nude mouse xenograft cancer model and humanized mouse model. KIF2C expression was higher in EC. Knockdown of KIF2C prolonged the G1 phases and inhibited EC cell proliferation, migration, and invasion in vitro. Bioinformatics analysis indicated that KIF2C is negatively correlated with the infiltration level of CD8 ${ }^{+} \mathrm{T}$ cells but positively with the poor prognosis of EC patients. The apoptosis of $\mathrm{CD}^{+} \mathrm{T}$ cell was inhibited after the knockdown of $\mathrm{KIF} 2 \mathrm{C}$ and was further inhibited when it is combined with anti-PD1. Conversely, compared to the knockdown of KIF2C expression alone, the combination of anti-PD1 further promoted the apoptosis of Ishikawa and RL95-2 cells. Moreover, the knockdown of KIF2C inhibited the expression of Ki-67 and the growth of tumors in the nude mouse xenograft cancer model. Our study found that the antitumor efficacy was further evaluated by the combination of anti-PD1 and KIF2C knockdown in a humanized mouse model. This study indicated that KIF2C is a novel prognostic biomarker that determines cancer progression and also a target for the therapy of EC and correlated with tumor immune cells infiltration in EC.
\end{abstract}

\section{Introduction}

Endometrial cancer (EC) is the sixth most commonly diagnosed cancer in women, which threatens women's health and quality of life, increasing the disease risk and medical burden on society. It was estimated that there are 417,000 new cases and 97,000 deaths in 2020 [1]. In China, the EC incidence has an upward tendency [2]. Most patients are diagnosed at an early stage with a good prognosis. However, the prognosis of advanced, poorly differentiated, or special types of EC is extremely poor $[1,3]$. Therefore, exploring the pathogenesis and effective treatment targets of $\mathrm{EC}$ is of paramount importance to improve the prognosis of EC.
Kinesins are the microtubule-associated motor that produces mechanical work correlated with ATP hydrolysis [4]. Kinesin-13 is the branch of the kinesin superfamily of proteins and is the important regulator of microtubule dynamics during mitosis [5]. Kinesin family member 2A, kinesin family member $2 \mathrm{~B}$, and kinesin family member $2 \mathrm{C}$ (KIF2C) are three distinct genes encoding a member of kinesin-13, and KIF2C is the best-characterized member which located in the cytoplasm throughout the cell cycle [6, 7]. KIF2C is important for mitosis, participating in kinetochore-microtubule attachment, spindle assembly, chromosome congression, and segregation $[8,9]$. Increasing microtubule KIF2C protein levels increased chromosome instability [10]. Additionally, KIF2C has been 
identified in cytoskeletal remodeling during tumor metastasis $[11,12]$. KIF2C has also been reported as a putative oncogene that is highly expressed in hepatocellular carcinoma nonsmall-cell lung cancer, colorectal cancer, glioma, and gastric cancer [13-17]. Recently, increasing evidence indicated that $\mathrm{KIF} 2 \mathrm{C}$ is associated with the prognosis of EC $[18,19]$. However, its pathophysiological roles in EC remain uninvestigated.

The immune system is the core defense against cancer development and progression [20]. Tumor immunotherapies have triggered a paradigm shift in cancer therapy and have shown sustained clinical responses [21]. Currently, the most effective immunotherapies are immune checkpoint blocking (ICB) antibodies, which target inhibitory surface receptors expressed by $\mathrm{T}$ cells, particularly, programmed cell death receptor-1 (PD-1) [22]. Activated $\mathrm{CD} 8^{+} \mathrm{T}$ and $\mathrm{CD}^{+} \mathrm{T}$ cells expressed PD-1, and exhausted $\mathrm{CD}^{+} \mathrm{T}$ cells expressed PD-1 highly but showed diminished cytotoxic responding to antigens. In recent years, the importance of $\mathrm{CD}^{+} \mathrm{T}$ cells and the response to immunotherapy were studied [23]. A prior study reported that liver metastasis induced tumor-specific $\mathrm{CD}^{+} \mathrm{T}$ cell loss in preclinical models, which mirror the systemic $\mathrm{CD}^{+} \mathrm{T}$ cell loss and reduced immunotherapy efficacy observed in patients with liver metastasis [24]. High $\mathrm{CD}^{+} \mathrm{T}$ cells immune infiltration is found to be correlated with a good prognosis in melanoma [25]. The high density of direct $\mathrm{CD}^{+} \mathrm{T} / \mathrm{B}$ cell interactions also can predict patients with an excellent prognosis, who would receive less invasive treatment in oropharyngeal squamous cell carcinoma [26]. Pretreatment peripheral $\mathrm{CD} 8^{+} \mathrm{T}$ cell levels are associated with checkpoint blockade response [27]. Conversely, disfunction or less infiltration of $\mathrm{CD}^{+} \mathrm{T}$ cells in the TME also results in worse clinical outcomes in many other cancer therapies [28-30]. Therefore, promoting the function and infiltration of $\mathrm{CD}^{+} \mathrm{T}$ cells in the TME may contribute to the efficacy of cancer therapies.

NY-CO-58/KIF2C has been revealed as a tumor antigen by screening antibodies in colorectal cancer [31]. However, the role of KIF2C in EC and its potential mechanisms in influencing $\mathrm{CD}^{+} \mathrm{T}$ cell antitumor efficacy have not been explored.

Here, we investigated the expression of KIF2C in EC, which is correlated with the progress and prognosis of EC. We also blockade the PD1/PD-L1 pathway to inhibit the $\mathrm{CD}^{+} \mathrm{T}$ cells immunology in vitro and in vivo. The findings of our study indicate that KIF2C influences the prognosis of EC and as a target for the therapy of EC and correlated with tumor immune cell infiltration in EC.

\section{Materials and Methods}

This study was conducted following the Declaration of Helsinki (as revised in 2013).

2.1. Data Collection. Level 3 expression data and mRNA expression profiles (575 cases, including 23 normal cases, workflow type: HTseq-FPKM) were downloaded from The Cancer Genome Atlas (TCGA) database. Clinical characteristics regarding survival time for EC patients were also obtained from the TCGA and Gene Expression Omnibus (GEO) database. R software (version 3.5.2) or Practical Extraction and
Report Language (Perl) scripts [32] on JAVA software were used to process all data.

2.2. Gene Set Enrichment Analysis (GSEA). To explore the potential correlations underlying the effect of KIF2C expression on EC prognosis, we applied GSEA (v4.1.0) to identify biological pathways pertaining to EC pathogenesis-associated KIF2C regulatory networks [33]. KIF2C-high expression and KIF2C-low expression were the phenotype labels. Each analysis of gene set permutations was conducted 1000 times.

2.3. Cibersort. The "limma" package [34] was used to normalize transcriptome profiles of EC patients. Next, we performed the "CIBERSORT" scripts to assess the immune compositions of EC patients [35]. We considered that the selected samples were usable when $p<0.05$.

2.4. Patients' Sample. Twelve EC tissues and twelve adjacent tissues were collected from patients with who had undergone surgical resections or biopsies at the Department of Gynecology, Wuhan Union Hospital, from September 2019 to March 2021. Complete clinical data were available for all patients. At least two pathologists evaluated all specimens according to the World Health Organization (WHO) guidelines. This study was approved by The Ethics Committees of Union Hospital, Tongji Medical College, Huazhong University of Science and Technology. We obtained patients' permission before surgery. Tissues are placed in 10\% formalin immediately and embedded in paraffin for future use. The rest part of the tissue samples was immediately aliquoted frozen and stored in liquid nitrogen for further RNA and protein extraction.

2.5. Cell Culture. Human EC cell lines Ishikawa and RL95-2 were obtained from American Type Culture Collection (ATCC, Manassas, USA). Ishikawa cells were cultured in DMEM/F12 (Gibco, Thermo Fisher Scientific, Massachusetts/MA, USA) with 10\% fetal bovine serum (FBS, Biological Industries, Beit HaEmek, Israel) and $1 \%$ penicillin and streptomycin (PS, Boster, Wuhan, China) at $37^{\circ} \mathrm{C}$ under a humidified atmosphere of $5 \% \mathrm{CO}_{2}$. RL95-2 cells were cultured in DMEM/F12 supplemented with 10\% FBS, 1\% PS, and $1 \%$ insulin (Novo Nordisk, Copenhagen, Denmark) at $5 \% \mathrm{CO}_{2}$ and $37^{\circ} \mathrm{C}$.

2.6. Transfection. Lentivirus containing KIF2C-shRNA and shNC was also purchased from GenePharma (Shanghai, China). The effective KIF2C-shRNA sequences were $5^{\prime}$ CCAACGCAGUAAUGGUUUATT-3'. Seventy-two hours after transfection, WB was used to examine the KIF2CshRNA interference effect. Stable cells transfected with KIF2C-shRNA were obtained after 14 days of puromycin screening $(2 \mu \mathrm{g} / \mathrm{ml})$.

2.7. Reverse Transcription and Quantitative Real-Time Polymerase Chain Reaction ( $q R T-P C R)$ Analysis. Total RNA was isolated samples of cells and EC samples using RNAiso Plus (TaKaRa, Shiga, Japan) following manufacturer's protocol; cDNA was prepared using ABScript RT Master Mix (TaKaRa, Shiga, Japan). qRT-PCR was performed using the CFX Connect Real-Time System (Bio-Rad, California, USA) 
with primers specific for KIF2C, forward $5^{\prime}$-TCCAGGCAA TTTATCCAAGG-3', reverse $5^{\prime}$-CCAGTCTGGTCCTTGC TGTA- ${ }^{\prime}$; GAPDH, forward $5^{\prime}$-AGATCCCTCCAAAATC AAGTGG- $3^{\prime}$, reverse $5^{\prime}$-GGCAGAGATGATGACCCTT TT- $3^{\prime}$. Target gene expression was quantified relative to the expression of GAPDH using the comparative Ct $\left(2^{-\Delta \Delta C t}\right)$ method.

2.8. WB Analysis and Antibodies. WB assay was implemented as previously described [36]. The primary antibodies are against KIF2C (1:1000 dilution, Proteintech, Wuhan, China) and GAPDH (1:10000 dilution, ABclonal, Woburn, MA, USA). After incubation with peroxidase-labeled speciesspecific secondary antibodies (1:8000 dilution, ABclonal, Woburn, MA, USA), protein bands were visualized by ECL substrate (Servicebio, Wuhan, China) using Image Lab Software in Molecular Imager ${ }^{\circledR} \mathrm{ChemiDoc}^{\mathrm{TM}}$ XRS+ (Bio-Rad, California, USA).

2.9. Immunohistochemistry (IHC) Staining and Scoring. The EC tissues embedded in paraffin were sectioned into slices $4 \mu \mathrm{m}$ thick, and the slides were then deparaffinized and rehydrated. After being treated with 3\% hydrogen peroxide, the slides were incubated overnight at $4^{\circ} \mathrm{C}$ with the primary antibody KIF2C (1:500 dilution, Proteintech, Wuhan, China). After rinsing in PBS, the sections were incubated with peroxidase-labeled anti-rabbit immunoglobulin $\mathrm{G}$ (IgG) for $30 \mathrm{~min}$. Finally, all slides were incubated with DAB-Substrate (Beyotime, Shanghai, China) before being rinsed with distilled water, counterstained with haematoxylin, dehydrated, and mounted. A Motic microscope (Motic, Xiamen, China) was used to visualize and photograph the slides. Semiquantitative evaluation of IHC was performed by two observers who were blinded to the identity of the slides. Remmele and Schicketanz immunoreactive score (IRS) and immunohistochemical scores (IHS) were selected to analyze the data we obtained [37]. The multiplex fluorescent IHC staining intensity was obtained by image J. The IHS was determined based on the staining intensity (SI) and the percentage of immunoreactive cells (PR). The SI scale was divided into four categories $(0=$ no staining, $1=$ weak staining, $2=$ moderate staining, and $3=$ strong staining), and the PR scale was divided into five categories $(0=$ no staining, $1=1-10 \%$ staining, $2=11-50 \%$ staining, $3=51-80 \%$ staining, and $4=81-100 \%$ staining). A final semiquantitative score ranging from 0 to 12 points was calculated for each sample. Samples with IHS above 4 were considered positive, and those with IHS below 4 were considered negative [37].

2.10. Cell Proliferation Assay. Ishikawa and RL95-2 cells were seeded in 96-well plates (Nest Biotechnology, Wuxi, China) at the density of $2 \times 10^{3}$ and $4 \times 10^{3}$ per well, respectively. Cell-Counting Kit-8 (CCK8, Bimake, Houston, USA) was used to determine the cell proliferation following the user manual. The resulting absorbance at $450 \mathrm{~nm}$ was recorded using a spectrophotometer (ThermoFisher Scientific, Waltham, MA, USA). All CCK8 assays were conducted in triplicate.
2.11. Cell Migration and Invasion Assays. Transwell chambers of $8 \mu \mathrm{m}$ pore size (Corning Costar, Maine/ME, USA) were used to assess migration and invasion. Serum-free medium was used in the top chamber with Ishikawa $\left(8 \times 10^{4} /\right.$ well $)$ and RL95-2 $\left(1.2 \times 10^{5} /\right.$ well), respectively. The microfilters were precoated with $50 \mu \mathrm{l}$ of Matrigel matrix (BD Biosciences, Sparks, MD, USA) in invasion assays. The bottom chambers contained a chemo-attractant (medium with 10\% FBS). After 24-hour migration and invasion, the cells were then fixated and stained with $0.1 \%$ violet crystal (Servicebio, Wuhan, China). Cells that passed the membrane were counted and imaged in 3 random fields of the membrane using CX23 Olympus light microscopy (Olympus, Tokyo, Japan).

2.12. Colony Formation Assay. Ishikawa and RL95-2 cells were seeded into $8 \mathrm{~cm}^{2}$ dishes at a density of 700 and 1000 cells and then allowed to grow for 2 weeks. Cells were fixed with methanol (Servicebio, Wuhan, China) for $15 \mathrm{~min}$ and stained with $0.1 \%$ violet crystal (Servicebio, Wuhan, China) for $30 \mathrm{~min}$ and counted manually.

2.13. Flow Cytometry. After transfection of the shRNA and shNC for KIF2C, Ishikawa and RL95-2 cells $\left(1 \times 10^{6}\right)$ were collected with EDTA (Gibco, ThermoFisher Scientific, Waltham, MA, USA) and washed three times with phosphate-buffered saline (PBS, Servicebio, Wuhan, China) and fixed on ice with $70 \%$ ethanol. Flow cytometry was implemented as previously described [36].

2.14. Human-Activated $C D 8^{+} \mathrm{T}$ Cell Collection. Using a human lymphocyte separation medium (Dakewe, Shenzhen, China) isolated healthy human donor peripheral blood mononuclear cells (PBMCs). $\mathrm{CD}^{+} \mathrm{T}$ cells were isolated from PBMCs by magnetic bead purification using human $\mathrm{CD}^{+} \mathrm{T}$ cell microbeads (Miltenyi Biotec, Bergisch Gladbach, Germany). Then, the $\mathrm{CD}^{+} \mathrm{T}$ cells were cultured in Roswell Park Memorial Institute(RPMI-) 1640 medium with 10\% fetal bovine serum (Gibco, Thermo Fisher Scientific, MA, USA) and 1\% PS (Boster, Wuhan, China). Dynadeads ${ }^{\mathrm{TM}}$ human T-activator CD3/CD28 (Thermo Fisher Scientific, MA, USA) was used to $\mathrm{CD}^{+} \mathrm{T}$ cell expansion and activation [38].

2.15. In Vitro $C D 8^{+} T$ Cell Coculture System. In a 3-day incubation, magnetic bead-purified peripheral $\mathrm{CD}^{+} \mathrm{T}$ cells $\left(2 \times 10^{5}\right.$ cells/well in $21 \mathrm{~cm}^{2}$ plates $)$ were cocultured with Ishikawa and RL95-2 cells with shKIF2C and shNC at a 2:1 $\left(\mathrm{CD}^{+} \mathrm{T}\right.$ cell:tumor cell) ratio in $5 \mathrm{ml}$ complete RPMI-1640 medium, in the presence or absence of human monoclonal antibody PD-1 neutralizing antibody camrelizumab (SHR1210) (20 $\mu \mathrm{g} / \mathrm{ml}$, Heng Rui, Jiang Su, China) [39]. After 3-day incubation, the supernatants were harvested for $\mathrm{LDH}$ assay, and the $\mathrm{CD} 8^{+} \mathrm{T}$ cells were harvested for analysis of $\mathrm{CD}^{+} \mathrm{T}$ cells apoptosis. The proportion of apoptosis $\mathrm{CD}^{+} \mathrm{T}$ cell was examined using $\mathrm{PE}$ annexin $\mathrm{V}$ apoptosis detection kit (BD Biosciences, New Jersey, USA). Flow cytometry was performed using the FACSVerse flow cytometer (BD Biosciences, New Jersey, USA), and the data were analyzed with FlowJo software (TreeStar, USA). 
2.16. Lactate Dehydrogenase (LDH) Assay. LDH is a cytoplasmic enzyme in cells and releases rapidly after the plasma membrane is damaged. Thus, $\mathrm{LDH}$ is used as an indicator of necrotic cell death [40]. $\mathrm{CD}^{+} \mathrm{T}$ cells cocultured with Ishikawa and RL95-2 cells with shKIF2C and shNC at a 2:1 ( $\mathrm{CD}^{+} \mathrm{T}$ cell : tumor cell) ratio; after a 3 -day incubation, the cell culture supernatant was collected, and the level of LDH was detected by LDH cytotoxicity assay detection kit (Beyotime, Shanghai, China) according to manufacturer's protocol.

2.17. Nude Mouse Xenograft Cancer Model. All animal studies were performed according to the protocols approved by Tongji Medical College's Animal Care and Use Committee. BALB/c-nu nude mice were purchased from China Beijing Vital River and housed in a standard pathogen-free environment laboratory. The mice were randomized into two groups. Xenografts were initiated by subcutaneous injection of total $1 \times 10^{6}$ negative or KIF2C-silenced Ishikawa cells in $100 \mu \mathrm{l}$ PBS into the right flank of Bulb/c nude mice. After 15 days, the mice were euthanized, and the weight of xenografts was recorded. Tumor volumes were measured using the formula (length $\times$ width $^{2}$ )/2. Tumor samples were partially embedded in paraffin for histopathological analysis.

To test the suppressive effect of PD-L1 ${ }^{+}$EC cells on $\mathrm{CD}^{+} \mathrm{T}$ cells immunity in vivo, we treated the mice with a subcutaneous injection of a total of $5 \times 10^{6}$ Ishikawa cells and with intravenous injection activated $\mathrm{CD}^{+} \mathrm{T}$ cells $\left(2.0 \times 10^{6}\right)$ from human PBMCs [41]. For in vivo checkpoint blockade, 5-week mice were administrated with $250 \mu \mathrm{g}$ PD1 monoclonal antibody through intraperitoneal injection (IP) three times [42].

2.18. Statistical Analysis. The correlations between the expression of KIF2C and clinical features were evaluated by the logistic regression and Wilcoxon signed-rank test. The KIF2C expression of the EC cohort was obtained using box plots. Clinical factors associated with OS in EC were identified using the Cox regression and Kaplan-Meier method. Quantitative values are expressed as the means \pm SEM. Student's $t$-test or one-way ANOVA was used to compare multiple groups. Correlation analysis was performed by the Spearman rank test. Statistical significance was defined as $p$ value $<0.05$.

\section{Results}

3.1. KIF2C Is Highly Expressed in EC and Correlated with the Expression of $C D 8^{+} \mathrm{T}$ Cells. In this study, we determined the KIF2C mRNA expression by qRT-PCR (Figure 1(a)). Using $\mathrm{WB}$, we analyzed the expression level of KIF2C in 12 cases of $\mathrm{EC}$ tissue and 12 normal endometrium cases (Figures 1(b) and $1(\mathrm{c})$ ). As shown, KIF2C was located in the cytoplasm according to IHC (Figure 1(d)). Moreover, these results showed that the KIF2C expression level was significantly higher in EC samples compared with normal endometrium samples. To elucidate the expression of KIF2C and the significance of upregulation of KIF2C in EC, we mined the publicly available databases Gene Expression Omnibus web- site (GEO; https://www.ncbi.nlm.nih.gov/geo/) and TCGA. The correlation of KIF2C expression with patients' clinicopathological features in primary EC was shown in Table 1. We analyzed the microarray dataset from TCGA containing 552 tumor samples and 23 normal samples. KIF2C expression was higher in EC samples than in control group samples (Figure 1(e)). We then analyzed 23 paired samples from TCGA and GSE17025 microarray datasets from GEO; also, the differential expression results were consistent with the overall results (Figures $1(\mathrm{f})$ and $1(\mathrm{~g})$ ). TCGA dataset analysis revealed that high-level expression of KIF2C is correlated with older age, vital status, higher pathologic grade, and higher clinical stage (Supplementary Figures 1(a)-1(d)). There are no significant differences between KIF2C expression and survival time (Supplementary Figure 1(e)), but KaplanMeier analysis showed that higher KIF2C expression was significantly associated with a low survival rate in the TCGA cohort (Figure 1(h)).

To analyze the relationship between the expression of KIF2C and immune-cell characteristics, we considered the current acknowledged methods to calculate the immune infiltration status among the samples from TCGA project of the uterine corpus endometrial carcinoma (UCEC) dataset including TIMER, XCELL, QUANTISEQ, MCPCOUNTER, EPIC, CIBERSORT-ABS, and CIBERSORT. The UCEC patients were divided into two groups according to the KIF2C expression level (high vs. low) based on the median expression values across all samples. Our results indicated that $\mathrm{CD} 8^{+} \mathrm{T}$ cell expression was negatively correlated with EC. Details about the subsets of infiltrating immune cells are shown in Figure 1(i). Hence, we investigated the relationship between KIF2C and the $\mathrm{CD} 8^{+} \mathrm{T}$ cell. KIF2C expression was negatively correlated with the levels of $\mathrm{CD}^{+} \mathrm{T}$ cell (Figure 1(j)). Similarly, the $\mathrm{CD}^{+} \mathrm{T}$ cell expression level is positively correlated with the cumulative survival of EC (Figure $1(\mathrm{k})$ ), which suggested that KIF2C may be involved in remodeling the tumor immune environment and thereby promoting the malignant progression of EC.

3.2. KIF2C Promotes Cell Proliferation, Migration, and Invasion In Vitro. The increased transcriptional level of KIF2C was correlated with aggressive tumor behavior in EC, which reveals that KIF2C may play an essential role in most EC tumor development. To validate this hypothesis, loss-offunction studies for KIF2C were performed in EC cell lines. We stably transfected with shKIF2C in Ishikawa and RL95-2 cells, leading to a decreased protein level of KIF2C compared to those in cells transfected with shNC (Figures 2(a) and 2(b)). We divided 552 TCGA UCEC samples into two groups (high vs. low) according to the median values of expression levels and performed GSEA to investigate the biological pathways in which KIF2C may be involved based on the c2.cp.kegg.v7.0.symbols.gmt gene set. Finally, we obtained 26 common pathways at FDR $<0.25$ and $p<0.05$. We selected the representative pathways and plotted the GSEA diagram including the cell cycle, DNA replication, ERBB signaling pathway, insulin signaling pathway, mismatch repair, oocyte meiosis, ubiquitin-mediated proteolysis, and P53 signaling pathway (Figure 2(c)). Based on the analysis of GSEA, we 


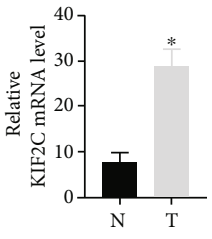

(a)

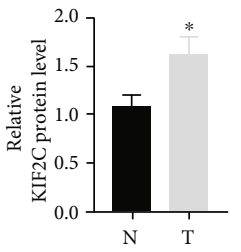

(c)

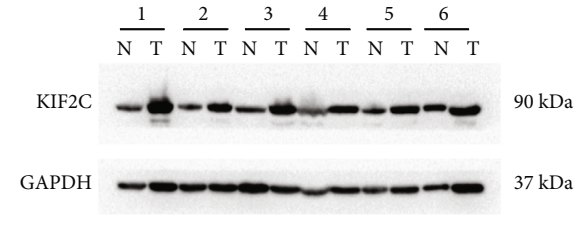

(b)
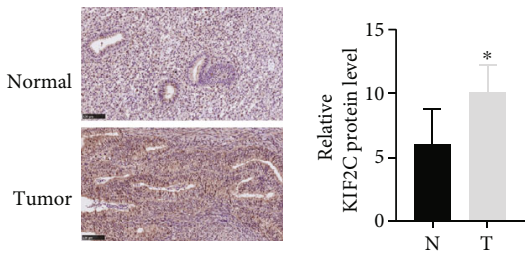

(d)
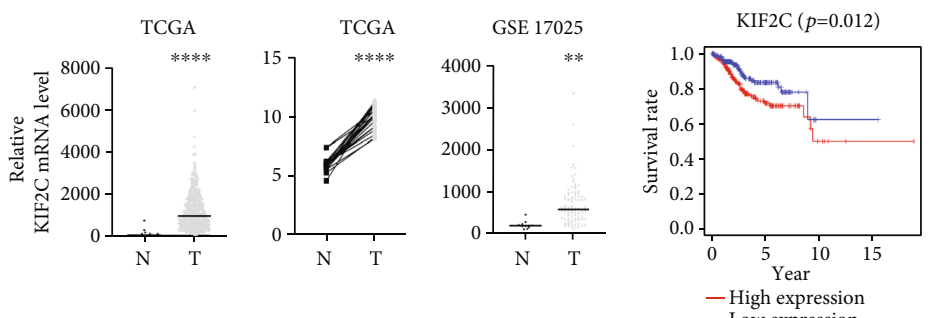

(e)

(f)

(g)

(h)

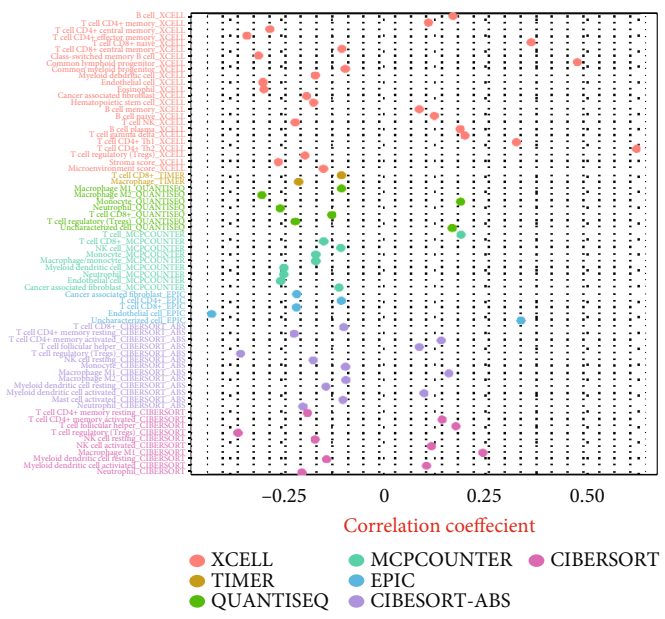

(i)
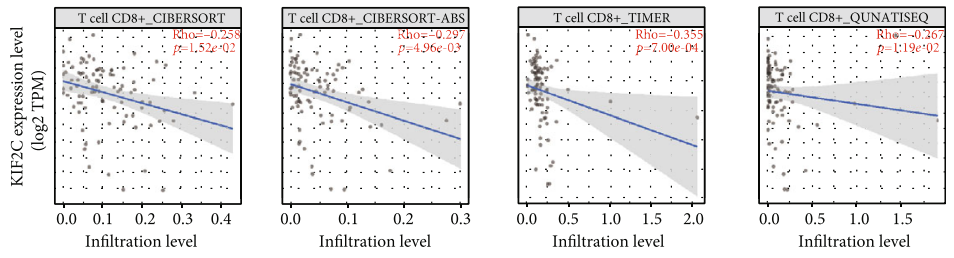

(j)

Figure 1: Continued. 

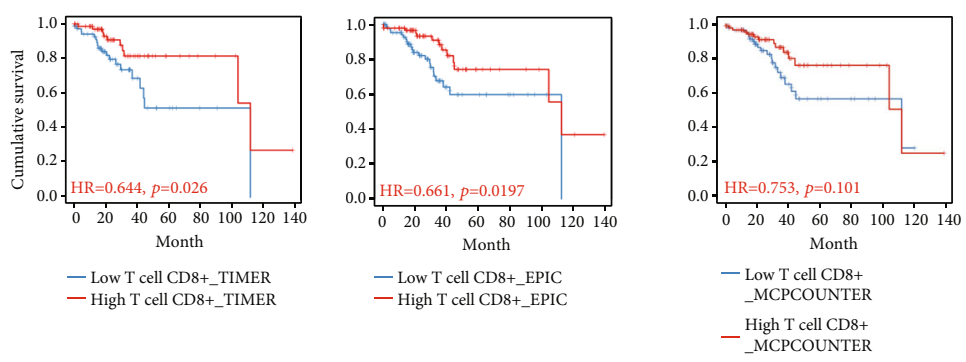

(k)

FIGURE 1: KIF2C is highly expressed in human EC and correlated with the level of immune infiltration. (a-d) The KIF2C mRNA and protein level was upregulated in fresh EC tissue, and determined by qRT-PCR (a), WB (b, c), and IHC (d). (e) Transcriptional level of KIF2C in EC (tumor) and benign endometrium (normal) tissues from the TCGA. (f) Upregulation of KIF2C mRNA level in EC of twenty-three paired samples from the TCGA. (g) KIF2C mRNA expression mined from GEO databases (GSE17025). (h) Kaplan-Meier survival curves compare high and low expression of KIF2C for survival rate in EC. (i) Correlation analysis between immune cells and EC in TCGA. (j) KIF2C expression is correlated with the $\mathrm{CD}^{+} \mathrm{T}$ cell infiltration level in EC. (k) Kaplan-Meier curves compare low and high expression of CD8 ${ }^{+}$ $\mathrm{T}$ cell infiltration level for cumulative survival in EC. T: endometrial cancer tissue; $\mathrm{N}$ : normal endometrium; error bars mean \pm SEM. ${ }^{*} p$ $<0.05 ;{ }^{* *} p<0.01 ;{ }^{* * *} p<0.001 ;{ }^{* * *} p<0.0001$.

TABLE 1: Correlation of KIF2C expression with patients' clinicopathological features in primary endometrial cancer.

\begin{tabular}{|c|c|c|c|}
\hline \multirow{2}{*}{ Parameter } & \multicolumn{2}{|c|}{ KIF2C expression } & \multirow{2}{*}{$p$ value } \\
\hline & Low & High & \\
\hline Age & $63(56-71)$ & $65(57-72)$ & 0.06 \\
\hline Clinical stage & & & $<0.01$ \\
\hline FIGO I & 224 & 115 & \\
\hline FIGO II & 25 & 26 & \\
\hline FIGO III & 59 & 65 & \\
\hline FIGO IV & 10 & 19 & \\
\hline Neoplasm histologic grade & & & $<0.01$ \\
\hline G1 & 92 & 6 & \\
\hline G2 & 98 & 22 & \\
\hline G3 & 128 & 197 & \\
\hline Histological type & & & $<0.01$ \\
\hline Endometrioid endometrial adenocarcinoma & 277 & 130 & \\
\hline Mixed serous and endometrioid & 10 & 12 & \\
\hline Serous endometrial adenocarcinoma & 31 & 83 & \\
\hline
\end{tabular}

found that KIF2C plays a pivotal role in the cell cycle. Subsequently, the potential roles of KIF2C in cell cycle regulation were validated. As shown in Figure 2(d), the G1 phases were significantly prolonged when KIF2C expression was reduced, which indicated that the knockdown of KIF2C could promote cell cycle arrest by restricting cells from entering the G2 phase.

Furthermore, Transwell and CCK8 assays were used to investigate cell migration, invasion, and proliferation. The Transwell assay revealed that the abilities of migration and invasion in Ishikawa and RL95-2 cells were inhibited when KIF2C was knocked down (Figures 2(e) and 2(f)). The colony formation assay also showed that the numbers of colonies were significantly reduced in KIF2C knockdown cells compared with control cells (Figure $2(\mathrm{~g})$ ). The results of the CCK8 assay indicated that the low expression of KIF2C significantly inhibited the viability of EC cells (Figure 2(h)).
3.3. Anti-PD1 Immunotherapy Enhances the Response to Inhibit EC Cells In Vitro. KIF2C overexpression was revealed to be correlated with reduced immune infiltration in lung adenocarcinoma [42]. Thus, we investigated the expression of KIF2C and PD-L1 in the EC tissues and Ishikawa cells. And we observed that the expression of PD-L1 is positively correlated with KIF2C (Figures 3(a) and 3(b)). To further validate whether upregulation of KIF2C contributed to the suppressive effects on $\mathrm{CD}^{+} \mathrm{T}$ cell immunity, Ishikawa and RL95-2 cells were stably transfected with shNC and shKIF2C and cocultured with in vitro-activated $\mathrm{CD}^{+} \mathrm{T}$ cells in $21 \mathrm{~cm}^{2}$ plates with or without anti-PD1. Then, $\mathrm{CD} 8^{+} \mathrm{T}$ cells were collected for flow cytometric analysis. Ishikawa transfected with shNC or shKIF2C cocultured with $\mathrm{CD} 8^{+} \mathrm{T}$ cells showed a higher percentage of apoptosis compared to that with $\mathrm{CD}^{+} \mathrm{T}$ cells and anti-PD1 antibody (Figures 3(c) 


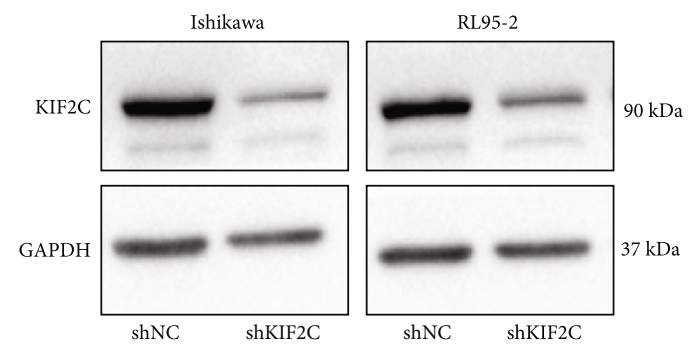

(a)

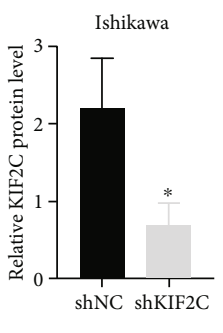

(b)

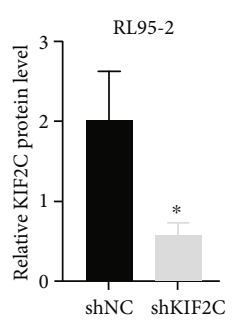

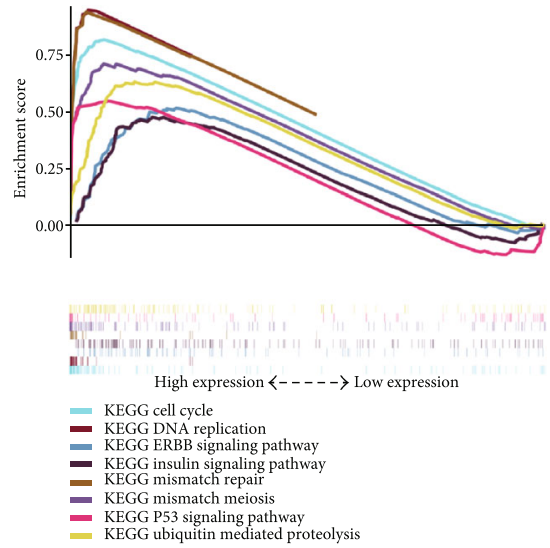

(c)

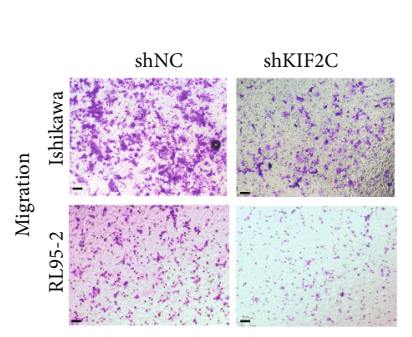

(e)

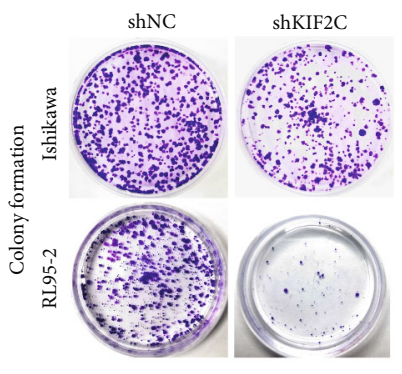

(g)
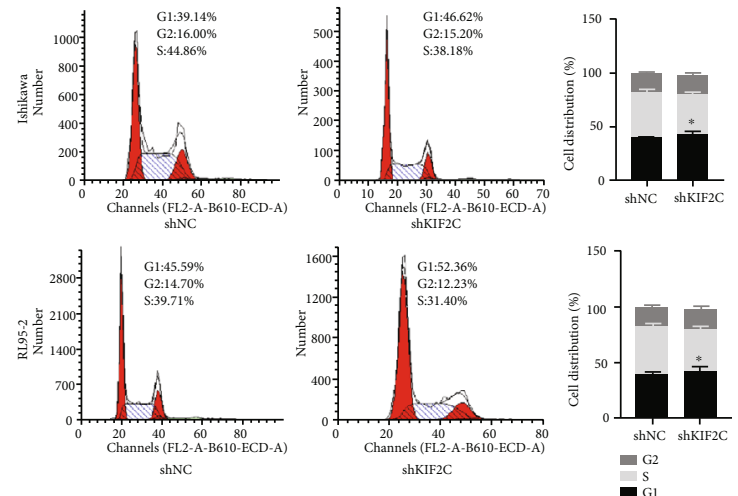

(d)
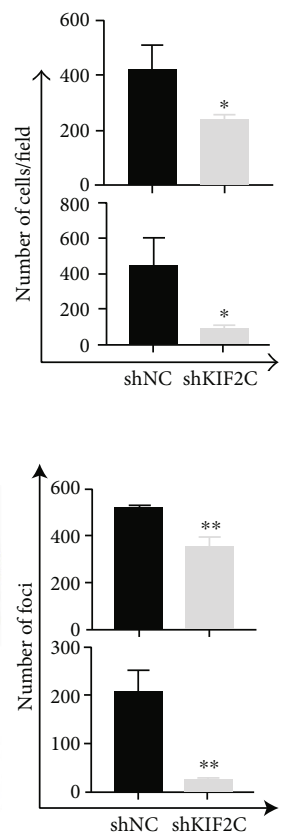

shNC shKIF2C

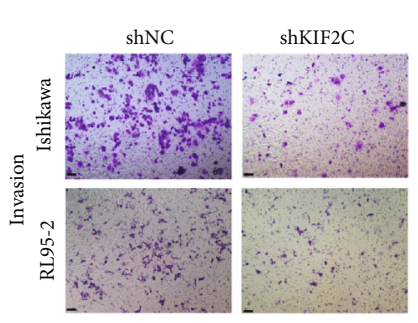

(f)

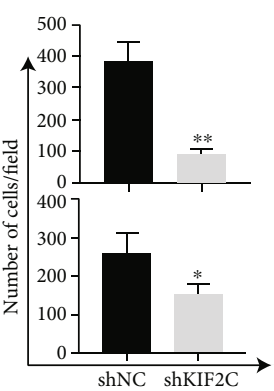

RL95-2
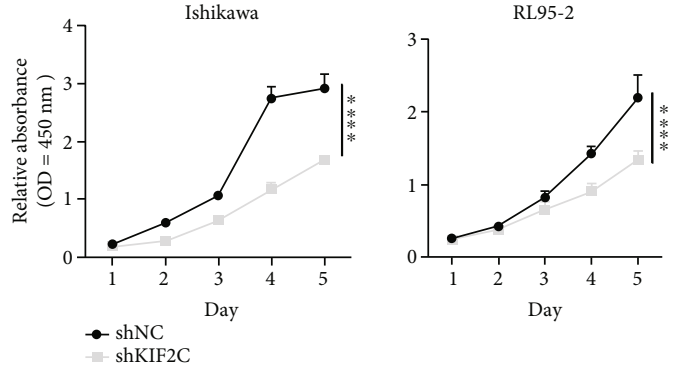

(h)

FIGURE 2: KIF2C expression is correlated with poor progress and outcomes in EC from the TCGA. (a, b) Knockdown the expression of KIF2C in Ishikawa and RL95-2 cells. (c) GSEA analysis suggests that KIF2C may be involved in some common signaling pathways, such as cell cycle, DNA replication, ERBB signaling pathway, oocyte meiosis, and ubiquitin-mediated proteolysis. (d) The cell cycle in Ishikawa and RL95-2 cells were analyzed by flow cytometry. (e-f) After being transfected with shNC and shKIF2C, the migration and invasion abilities of Ishikawa and RL95-2 cells were assessed by Transwell assay $(n=3)$. (g) The knockdown of KIF2C reduces the number of colonies in Ishikawa and RL95-2 cells (original magnification at $\times 100$; error bars mean \pm SEM; $n=3$ ). (h) CCK8 assays were performed to determine the effect of shKIF2C on cell growth in vitro. Scale bars, $200 \mu \mathrm{m}$; error bars mean \pm SEM; ${ }^{*} p<0.05 ;{ }^{* *} p<0.01 ;{ }^{* * *} p<0.001$. 


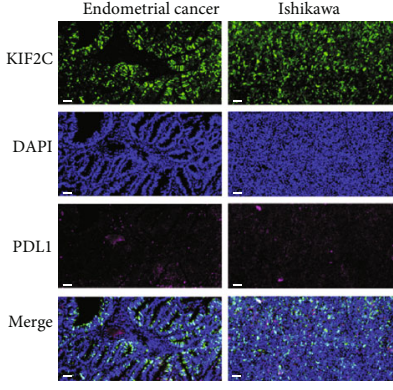

(a)

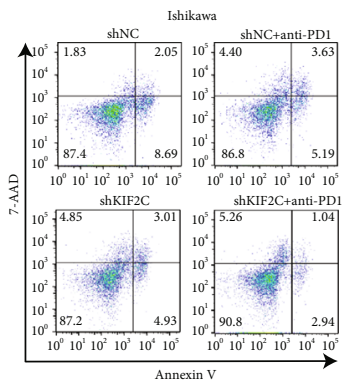

(c)

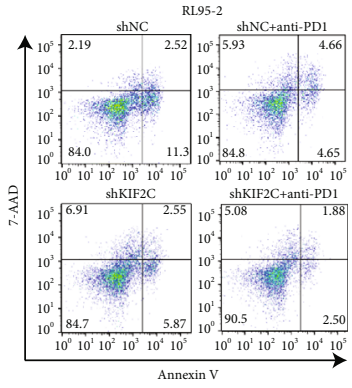

(e)

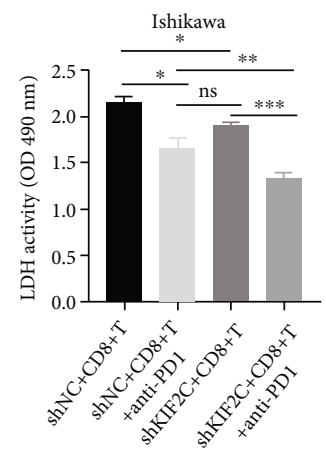

(g)

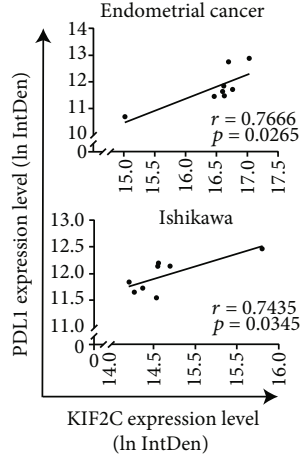

(b)

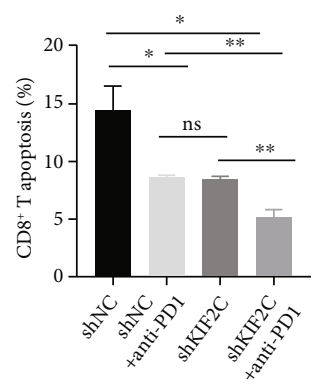

(d)

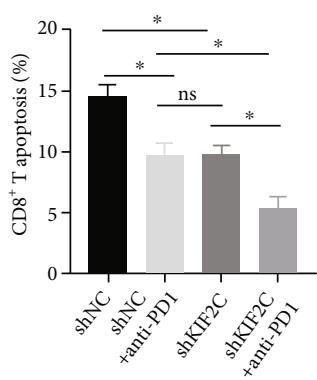

(f)

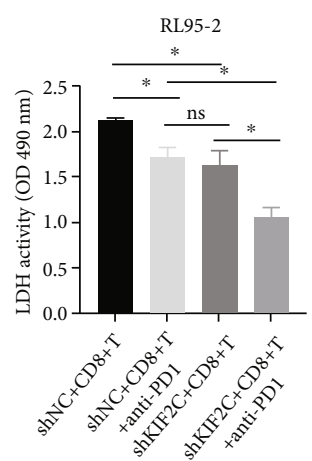

(h)

Figure 3: Anti-PD1 immunotherapy enhances the response to inhibit EC cells in vitro. (a) Representative images of KIF2C (green) and PDL1 (pink) in tumor tissues and Ishikawa cells were analyzed by multiplex fluorescent IHC (original magnification at $\times 200$ ). (b) The correlations between KIF2C and PD-L1 in human EC and Ishikawa cells. Results were expressed as log (ln) of integrated density in EC tissues and Ishikawa cells. (c-f) After being transfected with shNC or shKIF2C, Ishikawa and RL95-2 were cocultured for 3 days with activated CD8 ${ }^{+} \mathrm{T}$ cells, in the presence or absence of anti-PD1. Representative data and statistical analysis of T cell apoptosis were shown $(n=3)$. (g, h) The $\mathrm{LDH}$ released in cell cocultured supernatant was measured at the indicated time $(n=3)$. Scale bars, $50 \mu \mathrm{m}$; error bars mean \pm SEM. 


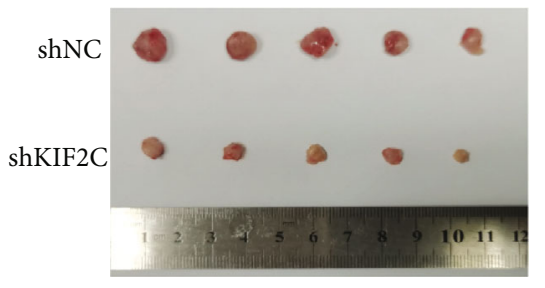

(a)

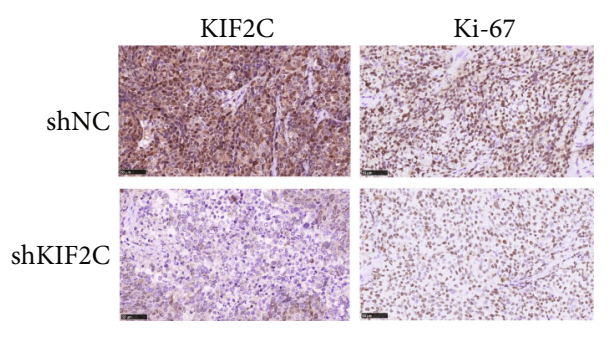

(d)

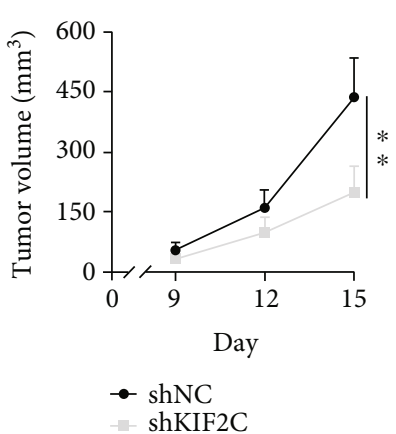

(b)

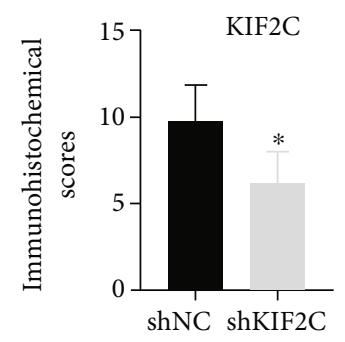

(e)

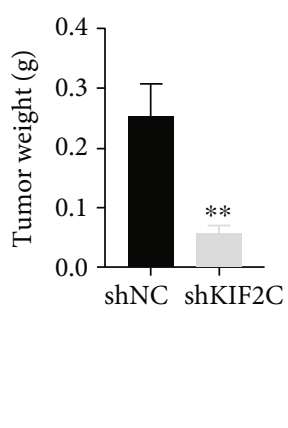

(c)

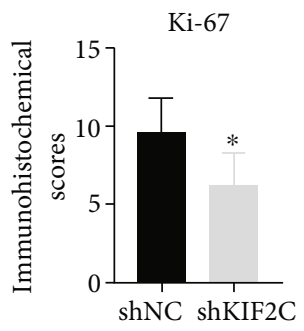

(f)

FIgURE 4: KIF2C promotes the growth of EC cells in vivo. (a) Representation xenograft tumors formed by injection of Ishikawa cells. (b, c) The volume and weight of the xenograft were measured. (d-f) The IHC analyses of KIF2C and ki-67 in xenograft tumors (original magnification at $\times 400)$. Scale bars, $50 \mu \mathrm{m}$. Error bars mean \pm SEM. ${ }^{*} p<0.05 ;{ }^{* *} p<0.01$.

and 3(d)). And the results of RL95-2 cells cocultured with $\mathrm{CD}^{+} \mathrm{T}$ cell and PD1 antibody are consistent with the results in Ishikawa cells (Figures 3(e) and 3(f)), which revealed that the reduced KIF2C expression inhibits the apoptosis of $\mathrm{CD}^{+} \mathrm{T}$ cells, and the anti-PD1 antibody further inhibits the apoptosis of $\mathrm{CD} 8^{+} \mathrm{T}$ cells.

Moreover, $\mathrm{LDH}$ is a stable cytoplasmic enzyme in all cells, which can release rapidly following plasma membrane damage. To demonstrate the apoptosis of coculture of tumor cells and $\mathrm{CD} 8^{+} \mathrm{T}$ cells, samples were collected by taking the supernatant of culture at the time of $\mathrm{CD}^{+} \mathrm{T}$ cells were collected, and an LDH assay was carried out. The results of the LDH assay were consistent with cytometric analysis (Figures $3(\mathrm{~g})$ and $3(\mathrm{~h})$ ). Thus, KIF2C contributes to the immune suppression of $\mathrm{CD}^{+} \mathrm{T}$ cells in the progress of EC.

3.4. KIF2C Promotes the Growth of EC Cells In Vivo. To investigate the role of the KIF2C in EC in vivo, we established a subcutaneous graft tumor model using Ishikawa cells in nude mice. Ishikawa cells stably transfected with shNC and shKIF2C were subcutaneously injected into nude mice. As expected, the implanted tumors generated from the shKIF2C group grew dramatically slower than those generated from shNC group (Figure 4(a)). The tumor volume and weight were reduced dramatically in the shKIF2C group (Figures 4(b) and 4(c)). The IHC showed that KIF2C, as well as $\mathrm{Ki}-67$ protein expression, was evidently decreased in the shKIF2C group (Figures 4(d)-4(f)). These results revealed that KIF2C knockdown leads to EC cells growth restricted in vivo as displayed in vitro.
3.5. Blockade of PD1 on $C D 8^{+}$T Cell Immunity Inhibits Tumor Growth In Vivo. Because of the small size of the previously formed xenograft, we increased the number of inoculations when subcutaneous injection. To test the suppressive effect of PD1 on $\mathrm{CD}^{+} \mathrm{T}$ cell immunity in vivo, xenografts were initiated by subcutaneous injection of total $5 \times 10^{6}$ Ishikawa cells in $100 \mu \mathrm{l}$ PBS into the right flank of $\mathrm{Balb} / \mathrm{c}$ nude mice. We then asked whether the combination of $\mathrm{CD} 8^{+} \mathrm{T}$ cell and anti-PD1 antibody could potentiate the efficacy of EC cell growth in a xenograft mouse model. When the tumor volume reached $50-100 \mathrm{~mm}^{3}$, mice were treated with activated $\mathrm{CD} 8^{+} \mathrm{T}$ cell combination with anti-PD1 three times over 9 days (Figure 5(a)). There was a decrease in tumors in mice treated with $\mathrm{CD}^{+} \mathrm{T}$ cell and anti-PD1 compared with the control group. Mice treated with $\mathrm{CD} 8^{+} \mathrm{T}$ cell plus anti-PD1 antibody also showed decreased tumor proliferation (Figures 5(b) and $5(\mathrm{c})$ ). We also observed that the KIF2C expression level is negatively correlated with $\mathrm{CD}^{+} \mathrm{T}$ cells in xenograft (Figure 5(d)). The representative images are shown in Figure 5(e).

\section{Discussion}

It is generally accepted that KIF2C has been reported to be upregulated in several cancers and promoted tumor proliferation and progression. In mammary carcinogenesis, overexpression of KIF2C might be involved in breast carcinogenesis and is a promising therapeutic target as well as a prognostic biomarker for breast cancer [43-45]. Recently, studies have revealed that KIF2C is overexpressed in hepatocellular carcinoma tissues. High KIF2C protein promotes cell 


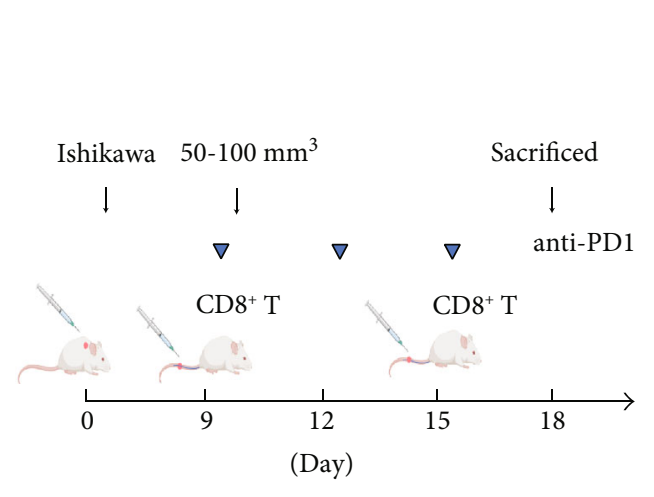

(a)

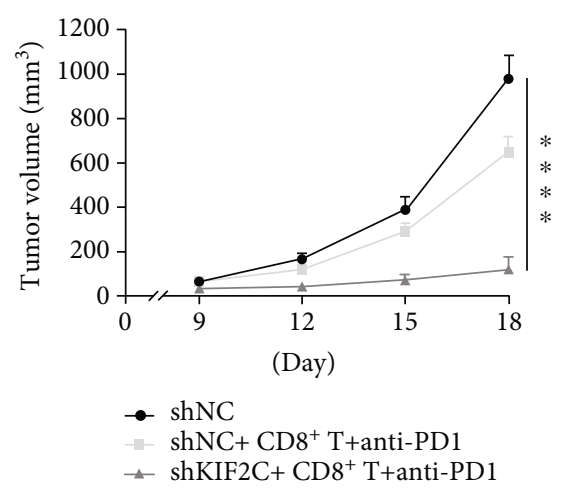

(c)

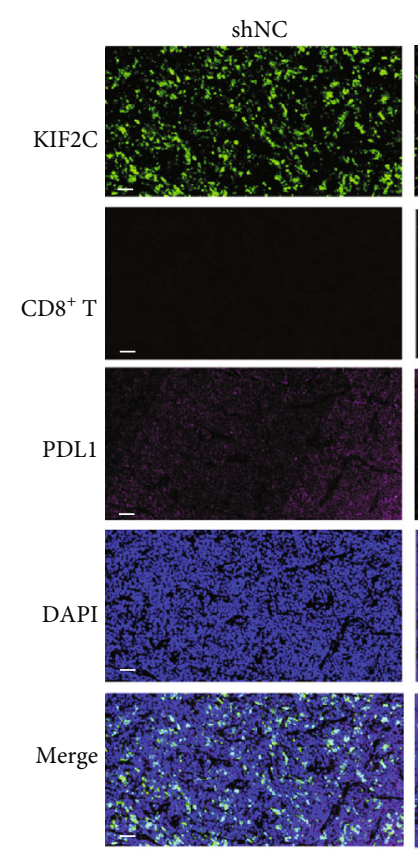

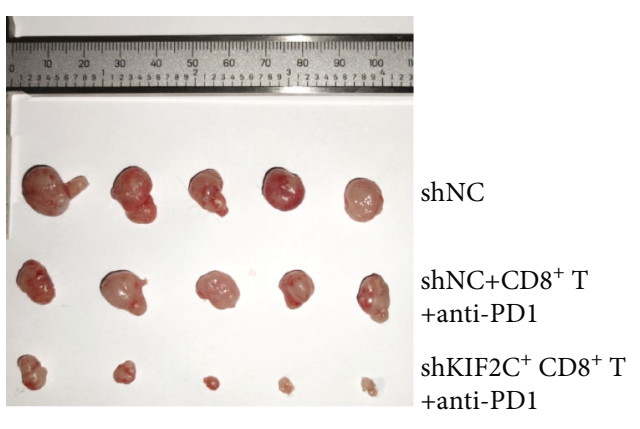

(b)

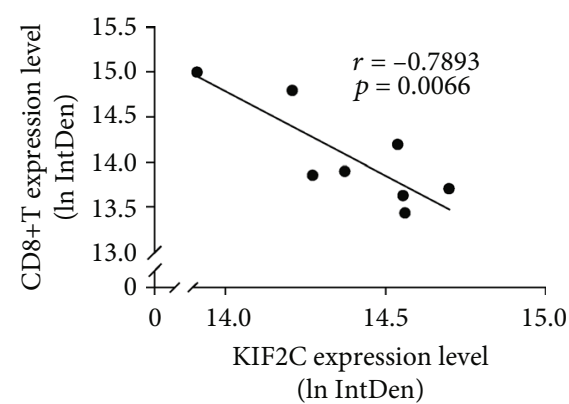

(d)
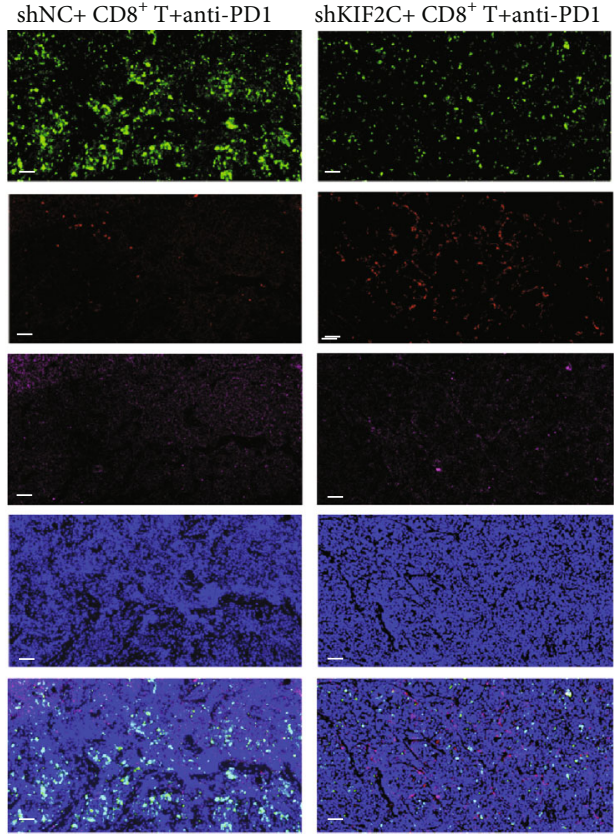

(e)

Figure 5: Blockade of PD1 on $\mathrm{CD}^{+} \mathrm{T}$ cell immunity inhibits tumor growth in vivo. (a) Mice were injected with human Ishikawa cells transfected with shKIF2C or shNC, the entailed injections with $\mathrm{CD}^{+} \mathrm{T}$ cell or $\mathrm{CD}^{+} \mathrm{T}$ cell in combination with an intraperitoneal injection of an anti-PD1 antibody. A schematic representation of the treatment was shown. (b, c) Representative images of tumors and a comparison of Ishikawa tumor growth in different groups were shown ( $n=5$ per group). (d) The correlation between KIF2C and CD8 ${ }^{+}$T cell in xenograft. Results were expressed as $\log (\ln )$ of integrated density in xenograft. Each dot in (d) represents 1 field. (e) Representative analysis of KIF2C (green), DAPI (blue), CD8 ${ }^{+} \mathrm{T}$ cell (red), and PDL1 (pink) in xenograft by multiplex fluorescent immunohistochemistry (original magnification at $\times 200)$. Scale bars, $50 \mu \mathrm{m}$. Error bars mean \pm SEM. ${ }^{*} p<0.05 ;{ }^{* *} p<0.01 ;{ }^{* * *} p<0.001 ;{ }^{* * * *} p<0.0001$. 
proliferation and predicts poor prognosis [46]. Similarly, overexpression of KIF2C promotes bladder cancer progression [47]. However, the expression and role of KIF2C in EC have not been fully elucidated. This study demonstrated that KIF2C plays an essential role in EC progression.

Over the past decades, accumulated evidence has emphasized that the KIF2C plays a pivotal role in a variety of biological activities. For example, KIF2C has been revealed as a target of the $\mathrm{mTORC} 1$ and $\mathrm{Wnt} / \beta$-catenin signaling in hepatocellular carcinoma [48]. KIF2C also exerts an oncogenic role and is negatively regulated by miR-325$3 p$ in non-small-cell lung cancer (NSCLC) [13]. Jung et al. reported that $\mathrm{KIF} 2 \mathrm{C}$ participates in the mechanism that lactate activates the E2F pathway to promote cell motility [49]. In breast cancer, comprehensive bioinformatics analyses revealed that tumor-related KIF2C correlated with poor outcomes of breast cancer patients and acts as a potential prognostic biomarker [45]. Here, we found that KIF2C was highly expressed in EC and associated with worse overall survival. This may be owing to the evidence that patients with high-level KIF2C expression have a higher advanced clinical stage, higher pathologic grade, and worse subtype. Employing loss-of-function studies, we demonstrated that decreasing KIF2C expression inhibited cell proliferation, migration, and invasion in vitro and inhibited tumor growth in vivo, suggesting an oncogenic role of KIF2C during EC progression. These results are consistent with a study that revealed that reduced KIF2C expression inhibits the migration and invasion of hepatocellular carcinoma [48].

To facilitate the elucidation of the biological function of the KIF2C in the development of EC, we performed GSEA. GSEA analysis showed that KIF2C was involved in the cell cycle. Using the flow cytometry assay, we confirmed that the knockdown of KIF2C could promote cell cycle arrest by restricting cells from entering the G2 phase, and this conclusion was consistent with those of a previously published study [50].

Anti-PD1 antibody enhances $\mathrm{CD}^{+} \mathrm{T}$ cell-mediated killing of tumor cells through removing $\mathrm{CD}^{+} \mathrm{T}$ cell suppressive signals from series of tumor-associated cells [51]. $\mathrm{Li}$ and Wan revealed the differences in immune phenotypes of the immune microenvironment in EC and defined four immune subtypes of $\mathrm{EC}$, and $\mathrm{CD}^{+} \mathrm{T}$ cells were correlated with EC patients' survival [52]. A recent study investigated that quantification of intraepithelial $\mathrm{CD}^{+} \mathrm{T}$ cells also improves the prognostic utility of the molecular EC classification in the early stage [53].

In our study, we analyzed the correlation between KIF2C expression and the level of immune cell infiltration in EC tissues, and we found that KIF2C was inversely correlated with $\mathrm{CD}^{+} \mathrm{T}$ cells level. This finding suggested that the expression of KIF2C in EC may be correlated with $\mathrm{CD}^{+} \mathrm{T}$ cells. So, we investigated the potential mechanisms of KIF2C in influencing $\mathrm{CD}^{+} \mathrm{T}$ cells' antitumor efficacy in vivo and cytotoxicity in vitro. Intriguingly, $\mathrm{CD}^{+} \mathrm{T}$ cells cocultured with Ishikawa and RL95-2 showed a higher percentage of apoptosis compared to that with anti-PD1 antibody. This further supports our hypothesis that blockade of PD1 on
$\mathrm{CD}^{+} \mathrm{T}$ cells immunity inhibits tumor growth in vitro and in vivo. However, the detailed mechanism needs to be further investigated.

In conclusion, our study sheds light on the biological and clinical significance of KIF2C in EC. Knockdown of KIF2C exerts a negative effect on cell proliferation, migration, and invasion. PD1 antibody blockade of immune receptors has proven to be effective in revitalizing exhausted $\mathrm{CD}^{+} \mathrm{T}$ cells. Targeting two or more receptors has a pivotal potential to increase the efficacy of immunotherapy. We find that the antitumor efficacy was further evaluated by the combination of anti-PD1 and KIF2C knockdown in a humanized mouse model. Our findings here suggest that KIF2C is a novel prognostic biomarker that determines cancer progression and also as a target for the therapy of EC, which correlated with tumor immune cells infiltration in EC.

\section{Data Availability}

Data that are directly related to the acquired results are available. For more detailed information, the readers can consult Lanfen An (email: alf9105@163.com).

\section{Ethical Approval}

The studies involving human participants were reviewed and approved by the Ethics Committee of Union Hospital, Tongji Medical College, Huazhong University of Science and Technology. All samples were obtained after receiving informed consent from the patients/participants.

\section{Conflicts of Interest}

The authors declare that the research was conducted in the absence of any commercial or financial relationships that could be construed as a potential of interest.

\section{Authors' Contributions}

Lanfen An, Jun Zhang, and Hongbo Wang conceived the idea and designed the experiments. Lanfen An, Dilu Feng, and Yingchao Zhao performed the experiments, obtained the data, and wrote the manuscript. Weixiang Ouyang, Rui Shi, Xing Zhou, and Zhicheng Yu participated in data analysis. Sitian Wei, Jie Min, and Hongbo Wang participated in the discussion and language editing. Jie Min and Hongbo Wang reviewed the manuscript. Lanfen An and Jun Zhang contributed equally to this work and shared the first authorship.

\section{Acknowledgments}

We would like to thank all the patients who participated in the study. This work was supported by the National Science Foundation of China (No. 81974409). 


\section{Supplementary Materials}

Correlation of KIF2C expression with patients' clinicopathological features in primary endometrial cancer (Figure s1). (Supplementary Materials)

\section{References}

[1] H. Sung, J. Ferlay, R. L. Siegel et al., "Global cancer statistics 2020: GLOBOCAN estimates of incidence and mortality worldwide for 36 cancers in 185 countries," CA: a Cancer Journal for Clinicians, vol. 71, no. 3, pp. 209-249, 2021.

[2] S. Ye, H. Wen, Z. Jiang, and X. Wu, "The effect of visceral obesity on clinicopathological features in patients with endometrial cancer: a retrospective analysis of 200 Chinese patients," BMC Cancer, vol. 16, no. 1, 2016.

[3] D. Nasioudis and K. Holcomb, "Incidence of isolated paraaortic lymph node metastasis in early stage endometrial cancer," European Journal of Obstetrics, Gynecology and Reproductive Biology, vol. 242, pp. 43-46, 2019.

[4] W. Wang, S. Cantos-Fernandes, Y. Lv et al., "Insight into microtubule disassembly by kinesin-13s from the structure of Kif2C bound to tubulin," Nature Communications, vol. 8, no. 1, article 91, 2017.

[5] L. Wordeman, "Microtubule-depolymerizing kinesins," Current Opinion in Cell Biology, vol. 17, no. 1, pp. 82-88, 2005.

[6] L. Wordeman and T. J. Mitchison, "Identification and partial characterization of mitotic centromere-associated kinesin, a kinesin-related protein that associates with centromeres during mitosis," The Journal of Cell Biology, vol. 128, no. 1, pp. 95-104, 1995.

[7] C. E. Walczak, T. J. Mitchison, and A. Desai, "XKCM1: a Xenopus kinesin-related protein that regulates microtubule dynamics during mitotic spindle assembly," Cell, vol. 84, no. 1, pp. 37-47, 1996.

[8] M. E. Tanenbaum, R. H. Medema, and A. Akhmanova, "Regulation of localization and activity of the microtubule depolymerase MCAK," BioArchitecture, vol. 1, no. 2, pp. 80-87, 2011.

[9] A. Shimo, C. Tanikawa, T. Nishidate et al., "Involvement of kinesin family member $2 \mathrm{C} /$ mitotic centromere-associated kinesin overexpression in mammary carcinogenesis," Cancer Science, vol. 1, no. 99, pp. 62-70, 2008.

[10] M. Wagenbach, J. J. Vicente, Y. Ovechkina, S. Domnitz, and L. Wordeman, "Functional characterization of MCAK/Kif2C cancer mutations using high-throughput microscopic analysis," Molecular Biology of the Cell, vol. 31, no. 7, pp. 580-588, 2020.

[11] A. Ritter, N. N. Kreis, F. Louwen, L. Wordeman, and J. Yuan, "Molecular insight into the regulation and function of MCAK," Critical Reviews in Biochemistry and Molecular Biology, vol. 51, no. 4, pp. 228-245, 2015.

[12] U. Eichenlaub-Ritter, "Microtubule dynamics and tumor invasion involving MCAK," Cell Cycle, vol. 14, no. 21, p. 3353, 2015.

[13] H. Gan, L. Lin, N. Hu et al., "KIF2C exerts an oncogenic role in nonsmall cell lung cancer and is negatively regulated by miR325-3p," Cell Biochemistry and Function, vol. 37, no. 6, pp. 424-431, 2019.

[14] Z. Zheng, L. Li, and J. Xie, "Kinesin family members KIF2$\mathrm{C} / 4 \mathrm{~A} / 10 / 11 / 14 / 18 \mathrm{~B} / 20 \mathrm{~A} / 23$ predict poor prognosis and pro- mote cell proliferation in hepatocellular carcinoma," Journal of Cancer, vol. 12, no. 3, pp. 899-911, 2021.

[15] L. Bie, G. Zhao, Y. Wang, and B. Zhang, "Kinesin family member $2 \mathrm{C}$ (KIF2C/MCAK) is a novel marker for prognosis in human gliomas," Clinical Neurology and Neurosurgery, vol. 114, no. 4, pp. 356-360, 2012.

[16] K. Ishikawa, Y. Kamohara, F. Tanaka et al., "Mitotic centromere-associated kinesin is a novel marker for prognosis and lymph node metastasis in colorectal cancer," British Journal of Cancer, vol. 98, no. 11, pp. 1824-1829, 2008.

[17] Y. Nakamura, F. Tanaka, N. Haraguchi et al., "Clinicopathological and biological significance of mitotic centromere- associated kinesin overexpression in human gastric cancer," British Journal of Cancer, vol. 97, no. 4, pp. 543-549, 2007.

[18] W. Zhang, L. Gao, C. Wang et al., "Combining bioinformatics and experiments to identify and verify key genes with prognostic values in endometrial carcinoma," Journal of Cancer, vol. 11, no. 3, pp. 716-732, 2020.

[19] X. Fu, S. Cheng, W. Wang et al., "TCGA dataset screening for genes implicated in endometrial cancer using RNA- seq profiling," Cancer Genetics, vol. 254-255, pp. 40-47, 2021.

[20] J. A. Marin-Acevedo, E. O. Kimbrough, and Y. Lou, "Next generation of immune checkpoint inhibitors and beyond," Journal of Hematology \& Oncology, vol. 14, no. 1, p. 45, 2021.

[21] Y. He, L. Fu, Y. Li et al., "Gut microbial metabolites facilitate anticancer therapy efficacy by modulating cytotoxic $\mathrm{CD}^{+} \mathrm{T}$ cell immunity," Cell Metabolism, vol. 33, no. 5, pp. 9881000.e7, 2021.

[22] K. E. Yost, H. Y. Chang, and A. T. Satpathy, "Recruiting T cells in cancer immunotherapy," Science, vol. 372, no. 6538, pp. 130-131, 2021.

[23] J. Edwards, J. S. Wilmott, J. Madore et al., "CD103+TumorResident CD8+T cells are associated with improved survival in Immunotherapy-Naïve melanoma patients and expand significantly during anti-PD-1 treatment," Clinical Cancer Research, vol. 24, no. 13, pp. 3036-3045, 2018.

[24] J. Yu, M. D. Green, S. Li et al., "Liver metastasis restrains immunotherapy efficacy via macrophage-mediated $\mathrm{T}$ cell elimination," Nature Medicine, vol. 27, no. 1, pp. 152-164, 2021.

[25] W. M. Song, P. Agrawal, R. von Itter et al., "Network models of primary melanoma microenvironments identify key melanoma regulators underlying prognosis," Nature Communications, vol. 12, no. 1, p. 1214, 2021.

[26] K. Hladíková, V. Koucký, J. Bouček et al., “Tumor-infiltrating B cells affect the progression of oropharyngeal squamous cell carcinoma via cell-to-cell interactions with CD8 + T cells," Journal for Immunotherapy of Cancer, vol. 7, no. 1, p. 261, 2019.

[27] B. Y. Nabet, M. S. Esfahani, E. J. Moding et al., "Noninvasive early identification of therapeutic benefit from immune checkpoint inhibition," Cell, vol. 183, no. 2, pp. 363376.e13, 2020.

[28] T. F. Gajewski, H. Schreiber, and Y. X. Fu, "Innate and adaptive immune cells in the tumor microenvironment," Nature Immunology, vol. 14, no. 10, pp. 1014-1022, 2013.

[29] R. Houot, L. M. Schultz, A. Marabelle, and H. Kohrt, “T-cellbased immunotherapy: adoptive cell transfer and checkpoint inhibition," Cancer Immunology Research, vol. 3, no. 10, pp. 1115-1122, 2015.

[30] P. Yu and Y.X. Fu, "Tumor-infiltrating T lymphocytes: friends or foes?," Laboratory Investigation, vol. 86, no. 3, pp. 231-245, 2006. 
[31] S. Gnjatic, Y. Cao, U. Reichelt et al., "NY-CO-58/KIF2C is overexpressed in a variety of solid tumors and induces frequent T cell responses in patients with colorectal cancer," International Journal of Cancer, vol. 127, no. 2, pp. 381-393, 2010.

[32] S. J. Goodswen, C. Gondro, N. S. Watson-Haigh, and H. N. Kadarmideen, "FunctSNP: an R package to link SNPs to functional knowledge and dbAutoMaker: a suite of Perl scripts to build SNP databases," BMC Bioinformatics, vol. 11, no. 1, p. $311,2010$.

[33] A. Subramanian, P. Tamayo, V. K. Mootha et al., "Gene set enrichment analysis: a knowledge-based approach for interpreting genome-wide expression profiles," Proceedings of the National Academy of Sciences of the United States of America, vol. 102, no. 43, pp. 15545-15550, 2005.

[34] M. E. Ritchie, B. Phipson, D. I. Wu et al., "limma powers differential expression analyses for RNA-sequencing and microarray studies," Nucleic Acids Research, vol. 43, no. 7, p. e47, 2015.

[35] A. M. Newman, C. L. Liu, M. R. Green et al., "Robust enumeration of cell subsets from tissue expression profiles," Nature Methods, vol. 12, no. 5, pp. 453-457, 2015.

[36] S. Chi, Y. Liu, X. Zhou et al., "Knockdown of long non-coding HOTAIR enhances the sensitivity to progesterone in endometrial cancer by epigenetic regulation of progesterone receptor isoform B," Cancer Chemotherapy and Pharmacology, vol. 83, no. 2, pp. 277-287, 2019.

[37] W. Remmele and K. H. Schicketanz, "Immunohistochemical determination of estrogen and progesterone receptor content in human breast cancer: Computer-assisted image analysis (QIC score) vs. subjective grading (IRS)," Pathology Research Practice, vol. 189, no. 8, pp. 862-866, 1993.

[38] C. Zhou, Y. Zhang, R. Yan et al., "Exosome-derived miR-142$5 p$ remodels lymphatic vessels and induces IDO to promote immune privilege in the tumour microenvironment," Cell Death, Differentiation, vol. 28, no. 2, pp. 715-729, 2021.

[39] C. Wang, K. B. Thudium, M. Han et al., "In vitro characterization of the anti-PD-1 antibody nivolumab, BMS-936558, and in vivo toxicology in non-human primates," Cancer Immunology Research, vol. 2, no. 9, pp. 846-856, 2014.

[40] L. Abdel-Latif, B. K. Murray, R. L. Renberg et al., "Cell death in bovine parvovirus-infected embryonic bovine tracheal cells is mediated by necrosis rather than apoptosis," The Journal of General Virology, vol. 87, no. 9, pp. 2539-2548, 2006.

[41] C. Zhou, W. Wei, J. Ma et al., "Cancer-secreted exosomal miR1468-5p promotes tumor immune escape via the immunosuppressive reprogramming of lymphatic vessels," Molecular Therapy, vol. 29, no. 4, pp. 1512-1528, 2021.

[42] D. K. Chiu, V. W. Yuen, J. W. Cheu et al., "Hepatocellular carcinoma cells up-regulate PVRL1, stabilizing PVR and inhibiting the cytotoxic T-cell response via TIGIT to mediate tumor resistance to PD1 inhibitors in mice," Gastroenterology, vol. 159, no. 2, pp. 609-623, 2020.

[43] G. Chen, M. Yu, J. Cao et al., "Identification of candidate biomarkers correlated with poor prognosis of breast cancer based on bioinformatics analysis," Bioengineered, vol. 12, no. 1, pp. 5149-5161, 2021.

[44] A. Shimo, T. Nishidate, T. Ohta, M. Fukuda, Y. Nakamura, and T. Katagiri, "Elevated expression of protein regulator of cytokinesis 1, involved in the growth of breast cancer cells," Cancer Science, vol. 98, no. 2, pp. 174-181, 2007.
[45] T. Li, H. Zeng, Z. Shan et al., "Overexpression of kinesin superfamily members as prognostic biomarkers of breast cancer," Cancer Cell International, vol. 20, no. 1, 2020.

[46] X. Li, W. Huang, W. Huang et al., "Kinesin family members $\mathrm{KIF} 2 \mathrm{C} / 4 \mathrm{~A} / 10 / 11 / 14 / 18 \mathrm{~B} / 20 \mathrm{~A} / 23$ predict poor prognosis and promote cell proliferation in hepatocellular carcinoma," American Journal of Translational Research, vol. 12, no. 5, pp. 16141639, 2020.

[47] C. Yang, Q. Li, X. Chen et al., "Circular RNA circRGNEF promotes bladder cancer progression via miR-548/KIF2C axis regulation," Aging, vol. 12, no. 8, pp. 6865-6879, 2020.

[48] S. Wei, M. Dai, C. Zhang et al., "KIF2C: a novel link between $\mathrm{Wnt} / \beta$-catenin and mTORC1 signaling in the pathogenesis of hepatocellular carcinoma," Protein Cell, vol. 12, no. 10, pp. 788-809, 2020.

[49] Y. Jung, J. Cho, S. Park et al., "Lactate activates the E2F pathway to promote cell motility by up-regulating microtubule modulating genes," Cancers, vol. 11, no. 3, p. 274, 2019.

[50] A. Ganguly, R. Bhattacharya, and F. Cabral, "Cell cycle dependent degradation of MCAK: evidence against a role in anaphase chromosome movement," Cell Cycle, vol. 7, no. 20, pp. 3187-3193, 2008.

[51] S. L. Topalian, F. S. Hodi, J. R. Brahmer et al., "Safety, activity, and immune correlates of anti-PD-1 antibody in cancer," The New England Journal of Medicine, vol. 366, no. 26, pp. 24432454, 2012.

[52] B. L. Li and X. P. Wan, "Prognostic significance of immune landscape in tumour microenvironment of endometrial cancer," Journal of Cellular and Molecular Medicine, vol. 24, no. 14, pp. 7767-7777, 2020.

[53] N. Horeweg, M. de Bruyn, R. A. Nout et al., "Prognostic integrated image-based immune and molecular profiling in earlystage endometrial cancer," Cancer Immunology Research, vol. 8, no. 12, pp. 1508-1519, 2020. 